\title{
Detecting and staging podoconiosis cases in North West Cameroon: positive predictive value of clinical screening of patients by community health workers and researchers
}

Samuel Wanji ${ }^{12 *}$, Jonas A. Kengne-Ouafo 1,2, Fabrice R. Datchoua-Poutcheu ${ }^{2}$, Abdel Jelil Njouendou1,2, Dizzel Bita Tayong ${ }^{1,2}$, David D. Sofeu-Feugaing ${ }^{2,3}$, Nathalie Amvongo-Adjia ${ }^{2,4}$, Bridget A. Fovennso ${ }^{1,2}$, Yolande F. Longang-Tchounkeu ${ }^{2}$, Fasil Tekola-Ayele ${ }^{5}$, Peter A. Enyong ${ }^{1,2}$, Melanie J. Newport ${ }^{6}$ and Gail Davey ${ }^{6}$

\begin{abstract}
Background: The suitability of using clinical assessment to identify patients with podoconiosis in endemic communities has previously been demonstrated. In this study, we explored the feasibility and accuracy of using Community Health Implementers (CHIs) for the large scale clinical screening of the population for podoconiosis in North-west Cameroon.

Methods: Before a regional podoconiosis mapping, $193 \mathrm{CH}$ s and 50 health personnel selected from 6 health districts were trained in the clinical diagnosis of the disease. After training, $\mathrm{CHIs}$ undertook community screening for podoconiosis patients under health personnel supervision. Identified cases were later re-examined by a research team with experience in the clinical identification of podoconiosis.

Results: Cases were identified by CHIs with an overall positive predictive value (PPV) of 48.5\% [34.1-70\%]. They were more accurate in detecting advanced stages of the disease compared to early stages; $\mathrm{OR} 2.07,95 \% \mathrm{Cl}=1$. $15-3.73, p=0.015$ for all advanced stages). Accuracy of detecting cases showed statistically significant differences among health districts $(X 2=25.30, p=0.0001)$.

Conclusion: Podoconiosis being a stigmatized disease, the use of $\mathrm{CH}$ s who are familiar to the community appears appropriate for identifying cases through clinical diagnosis. However, to improve their effectiveness and accuracy, more training, supervision and support are required. More emphasis must be given in identifying early clinical stages and in health districts with relatively lower PPVs.
\end{abstract}

Keywords: Podoconiosis, Screening, Predictive value, Community Health Implementers, Cameroon

\footnotetext{
* Correspondence: swanji@yahoo.fr

${ }^{1}$ Parasites and Vector Biology research unit (PAVBRU), Department of

Microbiology and Parasitology, University of Buea, Buea, Cameroon

${ }^{2}$ Research Foundation for Tropical Diseases and the Environment (REFOTDE),

Buea, Cameroon

Full list of author information is available at the end of the article
} 


\section{Background}

Access to comprehensive healthcare services of high quality is difficult for socio-economically disadvantaged groups in rural regions. This may be due to the lack of insurance, language barriers or cultural differences [1]. Health service programmes delivered by minimallytrained Community-based Health Implementers (CHIs), also known as Community-based Health Workers (CHWs), have been established in many developing countries [2]. This idea comes from a concept that has been around for at least 50 years [3]. According to a WHO Study Group [4], community health workers should be members of the communities in which they work, should be selected by the communities, should be answerable to the communities for their activities, should be supported by the health system but not necessarily a part of its organization, and have shorter training than professional workers [5, 6]. CHIs may be men or women, young or old, literate or illiterate [3]. Because they are generally indigenous to the communities in which they operate, sharing a common language, ethnicity, socio-economic status, or life experience, CHIs break the culture and language-related barriers between their own community and health care systems. As such, they are perceived by community members to be important sources of information on health issues and on how to access services.

Within the past 20 years, CHIs have been tremendously helpful in many preventive and promotive health programmes such as the African Programme for Onchocerciasis Control (APOC), in which they facilitate drug distribution. In this context, they are often referred to as community drug distributors. Depending on the setting, CHIs are referred to using many appellations: Community Health Volunteers, Village Health Workers, Basic Health Workers, Health Extension Workers, Lay Health Workers, Community Outreach Workers-this list is not exhaustive $[3,6,7]$. In malaria control programs, they have been shown to be very efficient in distribution of Insecticide-impregnated Bed Nets (IBNs) in the community. In addition, CHIs have been intensively used to provide prenatal care, vaccinations, vitamins and checkups, as well as to promote breastfeeding, oral rehydration, malaria treatment and fever management in remote areas $[6,8,9]$. The majority of these activities require limited diagnosis. Apart from a couple of interventions [10], CHIs have not been intensively used in programmes involving direct clinical screening of the population for a given disease. This may be feasible with diseases (e.g. non-communicable) whose screening approaches are based mostly on physical examination of the patient and to a lesser extent on biomedical examinations.

Podoconiosis is an example of such a disease. It is a geochemical disease mainly characterized by lymphedema which is a condition of localized fluid retention resulting from a compromised lymphatic system $[11,12]$. The main clinical feature of podoconiosis, oedema of the foot and lower leg, is similar to that observed in filarial infection due to Wuchereria bancrofti [13, 14]. In both diseases, lymphoedema progresses to elephantiasis. However, clinical manifestations such as epididymitis, lymph scrotum, hydrocele and chyluria are more specific to filarial infection [15]. Previous studies have documented the association of podoconiosis with irritant red clay soils, which are generated in areas at $1500 \mathrm{~m}$ above sea level (m a.s.l.), with $1000 \mathrm{~mm}$ annual rainfall and maximum temperatures of $20^{\circ} \mathrm{C}[12,16,17]$. The disease has been classified into five stages based on its severity with stage 1 being the least severe stage and stage 5 the most severe stage [18]. Apart from studies carried out by Price and Henderson [19] and Wanji et al. [20] little is known about the geographical distribution of podoconiosis in Cameroon. This study was designed prior to a regional mapping of podoconiosis in North West Cameroon to determine the aptitude and accuracy of CHIs in identifying and staging podoconiosis cases. Clinical examination is a valid means of diagnosing podoconiosis in endemic areas [7, 20]. A previous study in an endemic area in southern Ethiopia using community outreach workers demonstrated a predictive value of up to $100 \%$ [7]. The present study was intended to demonstrate the predictive value of $\mathrm{CHI}$ in the diagnosis of podoconiosis in Cameroon.

\section{Methods}

Study design

This study was designed to determine the feasibility of using Community Health Implementers (CHIs) to map podoconiosis in the North West region of Cameroon. Trained CHIs were employed to carry out a preliminary screening to identify podoconiosis cases in 6 of the 19 health districts of the North West region of Cameroon. In each district, with the aid of the health system, CHIs were selected from among the community drug distributors who had been working for years in the framework of the Community-Directed Treatment with Ivermectin (CDTI). To assess the accuracy of podoconiosis case identification by trained CHIs, all podoconiosis cases presumptively identified (suspected cases) were invited by the research team and re-examined.

\section{Study site}

This preliminary study was carried out in 6 health districts (Bafut, Bamenda, Batibo, Mbengwi, Ndop, Tubah) of the North West region of Cameroon. Nine health areas were selected from both Bafut and Tubah; 4 each from Bamenda, Batibo and Mbengwi and 13 from the Ndop health district (Fig. 1). The presence of podoconiosis had previously been demonstrated in the Ndop and Tubah health districts by Wanji et al [20] hence the selection of the region. The North West region is composed of mostly 


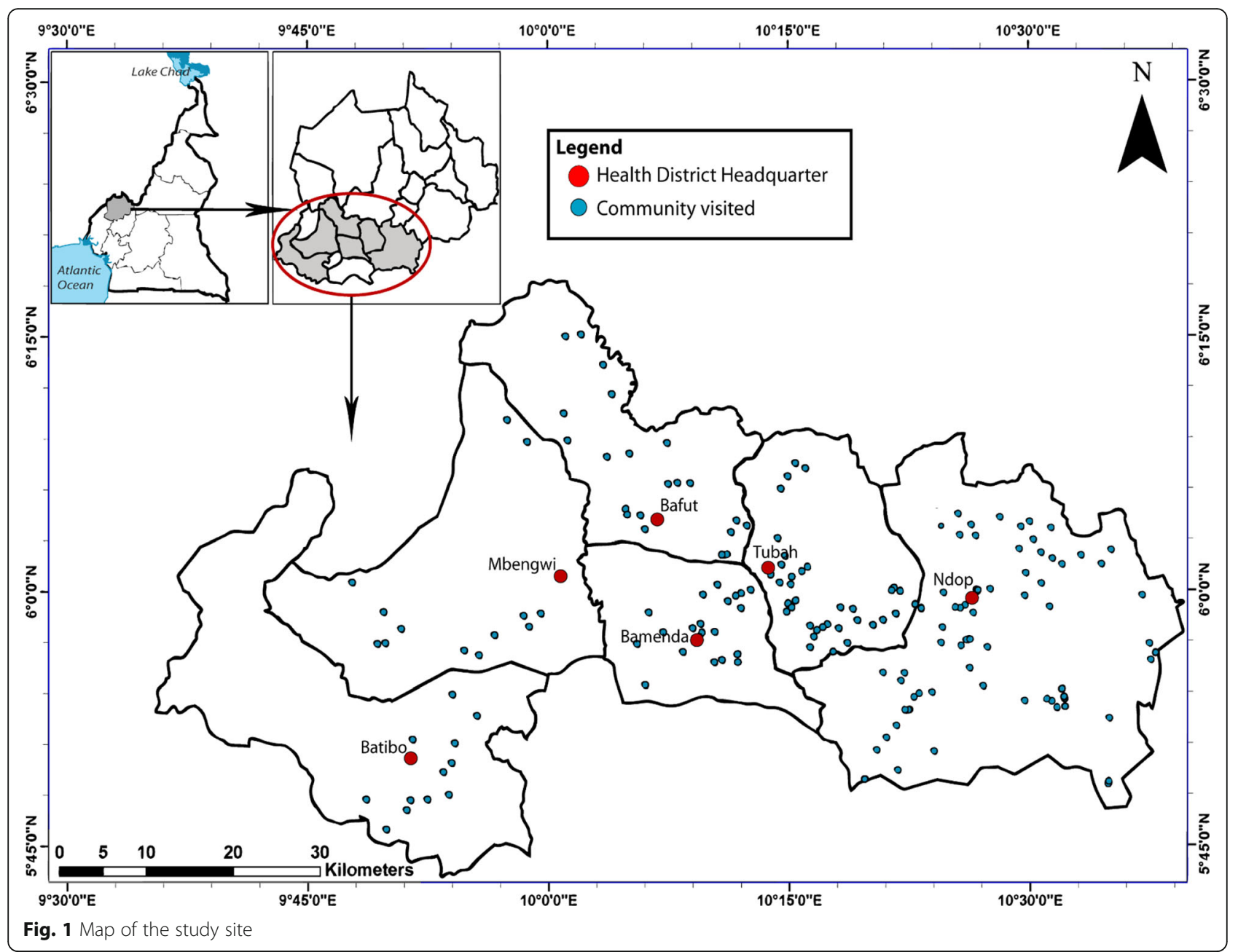

hilly land with a mean altitude of $1403 \mathrm{~m}$ above sea level. It experiences two seasons, the dry and the wet, and has a mean annual rainfall of $2500 \mathrm{~mm}$. The very fertile soils in the region are used to grow rice, maize, beans and other vegetables. The main occupation of the population is farming.

\section{Study population and ethical considerations}

The study population was made up of individuals of both sexes and more than 18 years of age who had lived in the area for at least 10 years. This criteria were necessary because podoconiosis is a chronic and debilitating disorder whose onset occurs after at least 10 years' exposure in endemic areas [21]. Prior to recruitment, the nature, objectives and potential benefits and risks of the study were explained to potential participants, and those who agreed to take part in the study signed a consent form. Participation was voluntary. The approach to the participants was made in accordance with the findings of rapid ethical assessment conducted by Kengne-Ouafo and colleagues [22]. This study was approved by the Cameroon Ethics Committee and the Ministry of Public Health.

\section{Training of community health implementers}

CHIs were invited from all the health areas in each health district. The training was done in 6 different pools (one per health district) by the research team. The trainees were made up of CHIs, health personnel and patients (for demonstration purposes). They were trained on the disease, its causes, clinical manifestations, stages, treatment, prevention and socio-economic impact. During the training, differences between podoconiosis and lymphatic filariasis were explained because many people found it difficult to differentiate between the two diseases. The training also focused on approach to the community and data recording. A practical exercise was conducted with photographs of the different podoconiosis stages including guidelines for their identification. 
Census in health districts, screening of the population for podoconiosis and validation

The census and screening of the population was carried out by CHIs under the supervision of health personnel. $\mathrm{CHIs}$ visited households in their quarters or zones, registered all individuals in each household, and did screening for podoconiosis. Research team members who had more experience in the diagnosis of podoconiosis reexamined the cases considered positive by the CHIs.

\section{Data analysis}

A template was created in EPI info v.3.5.3 and the data from registers was entered in it. The data were then cleaned and exported into SPSS version 20 (Chicago, IL, USA) after which point prevalences were computed. A point prevalence is the number of affected people in a health district divided by the total number of people registered, times 100\%. The Chi-squared test was used to compare prevalence data or proportions of individuals affected within health districts. CHIs' and researchers' findings were compared and an adjustment factor computed. The adjustment factor (positive predictive value) was defined as the ratio of total number of confirmed cases to the total number of suspected cases (present during the validation survey), times $100 \%$. Adjusted prevalence was also computed by multiplying the raw prevalence (obtained through CHIs screening) by the overall predictive value. The logistic regression model was used to measure the association between the accuracy of detecting real cases and disease stage.

\section{Results}

Training of Community Health Implementers and health personnel

A total of 6 training sessions were organised (one session per health district) during which 50 Chiefs of (health) Centres (COCs) and 193 CHIs were trained. Two CHIs were trained per health area in all Health Districts except in Ndop and Tubah where the number was increased with respect to the number and size of the communities. Table 1 presents the number of health areas, COCs and $\mathrm{CHIs}$ trained per health district. COCs and CHIs took part in the patient screening process with COCs playing a supervisory role.

\section{CHIs screening results}

Of 172 communities selected from 6 Health Districts, a total of 56,479 individuals were registered, among whom 1069 were identified as podoconiosis cases by CHIs giving an overall prevalence of $1.9 \%$. Prevalence ranged from $0.9 \%$ in Ndop to $7.7 \%$ in Batibo (Table 2). The prevalence was significantly different between districts $\left(x^{2}=1023.4 p<0.0001\right)$
Table 1 Participants trained per health district in the NorthWest region of Cameroon

\begin{tabular}{llll}
\hline Health District & $\begin{array}{l}\text { Number of Health } \\
\text { Areas targeted }\end{array}$ & $\begin{array}{l}\text { No of COCs } \\
\text { trained }\end{array}$ & $\begin{array}{l}\text { No of CHIs } \\
\text { trained }\end{array}$ \\
\hline BAFUT & 9 & 10 & 18 \\
BAMENDA & 4 & 5 & 8 \\
BATIBO & 4 & 5 & 8 \\
MBENGWI & 4 & 5 & 8 \\
NDOP & 14 & 15 & 103 \\
TUBAH & 9 & 10 & 48 \\
TOTAL & 42 & 50 & 193 \\
\hline
\end{tabular}

COCs Chiefs of Centre, CHIs Community Health Workers

Researchers' outcome and relationship between CHIs' and researchers' results (Positive predictive value)

During the validation survey, 326 of the 1069 cases previously identified by $\mathrm{CHIs}$ were present. Re-examination revealed 158 true podoconiosis cases giving an overall positive predictive value of $48.5 \%$. Predictive values varied between health districts with Ndop registering the highest (70\%) and Batibo, the lowest (34.1\%), with statistically significant differences $\left(x^{2}=25.30, p=0.0001\right)$. Among cases identified by the CHIs in the six districts, those in the Bafut, Bameda, and Batibo were at lesser odds of being accurate as validated by the research team compared to those identified in the Ndop district (Table 3).

\section{Predictive value with respect to podoconiosis stages}

In calculating the predictive value by podoconiosis stage, only 4 health districts were considered, because in Ndop and Tubah, the validation exercise was done globally without taking into account the different stages. The positive predictive value was found to increase with the severity of the disease. It ranged from $31 \%$ for stage 2 to $80 \%$ for stage 5 . Among cases identified by the CHIs those at advanced disease stage were at greater odds of being accurate as validated by the research team than early stage cases $(\mathrm{OR}=2.07,95 \% \mathrm{CI}=1.15-3.73 ; P=0.015)$ (Table 4). Stage 1, being a reversible stage, was not considered in this study.

\section{Discussion}

This study was designed to explore the feasibility of using CHIs in interventions necessitating clinical diagnosis of podoconiosis. The work was done prior to the regional mapping of podoconiosis using CHIs to assess how effective and accurate they could be in identifying people with this disease in their communities. CHIs were able to identify podoconiosis cases in the 6 selected health districts. Evaluation of their work revealed a mean positive predictive value of $48.5 \%$ (range 34 to $70 \%$ ). This value is low, and suggests CHIs do not accurately identify patients with podoconiosis in the community. A 
Table 2 Podoconiosis prevalence within the surveyed Health District

\begin{tabular}{|c|c|c|c|c|}
\hline Health District & Communities surveyed & Number registered $20^{\mathrm{a}}-10^{\mathrm{b}}$ (years) & Podoconiosis cases & Prevalence $(\%)$ \\
\hline BAFUT & 23 & 6077 & 304 & 5.1 \\
\hline BAMENDA & 21 & 12,457 & 134 & 1.1 \\
\hline BATIBO & 12 & 2918 & 227 & 7.7 \\
\hline MBENGWI & 11 & 1865 & 50 & 2.7 \\
\hline NDOP & 75 & 25,601 & 232 & 0.9 \\
\hline TUBAH & 30 & 7561 & 122 & 1.6 \\
\hline Total & 172 & 56,479 & 1069 & 1.9 \\
\hline
\end{tabular}

apeople who were more than 20 years old

${ }^{b}$ those who have lived in the community for more than 10 years

study carried out by Jacob and colleagues [23] revealed similar results. Trained community health workers diagnosed dementia with low sensitivity and positive predictive values (3.8 and $44.4 \%$ respectively).

Desta and colleagues [24] in southern Ethiopia demonstrated clinical diagnosis using Community Podoconiosis Agents (CPAs) to be appropriate in identifying patients in endemic areas where Wuchereria bancrofti infection is not suspected. Previous investigations showed the absence of such an infection in our setting [20]. However, the very high predictive value (100\%) obtained in Ethiopia could be explained by the fact that the survey was done by more experienced CPAs. The study was indeed carried out in southern Ethiopia, a region where a podoconiosis treatment and prevention association known as Mossy Foot Treatment and Prevention Association (MFTPA) had been operating for over a decade [25]. The MFTPA was organized into clinical and social work sections and operates by transforming treated patients into CPAs. CPAs had good knowledge of the disease and were highly motivated to work with the community. Although the selected CHIs in Cameroon had been working with the community and showed some degree of motivation, they had received their training (one session) just before the screening exercise. This could in part explain the low predictive value obtained. Another study carried out by Gaziano and colleagues [10] showed that trained community health workers (CHWs) could complete screening for cardiovascular diseases risk in a short timeframe with a high level of accuracy ( $96.8 \%$ agreement compared with the gold standard of a health professional). However, it should be noted that in their study, CHWs were trained for 1-2 weeks and only those who met the criteria to do fieldwork were recruited.

It was noticed during the validation process that CHIs often mistook patients with arthritis/rheumatism, varicose veins and diabetic peripheral neuropathy for stage 2 podoconiosis. However, they experienced less difficulty in identifying advanced podoconiosis stages as positive predictive value was seen to increase with disease severity (Table 5). More training in differential diagnosis should therefore be arranged for CHIs and all health personnel who play a supervisory role in many health intervention programmes to circumvent the problem of misdiagnosis of earlier stages precisely in districts. Moreover, training on real patients, particularly with focus on early clinical stages may help in the future. In this study, it was noticed that in two health districts (Tubah and Ndop) where practice during training was done on real patients, the odds of identifying podoconiosis cases correctly was significantly higher compared to other health districts where pictures were used for demonstration purpose. However there was not much significant difference between Ndop and Tubah districts, which were the areas where the 2008 survey was done. This implies that CHIs could have become more familiar with the disease

Table 3 Relationship between CHIs' and researchers' screening for podoconiosis in North West Cameroon

\begin{tabular}{|c|c|c|c|c|c|c|}
\hline Health District & $\begin{array}{l}\text { Expected cases invited } \\
\text { (by } \mathrm{CHIs} \text { ) }\end{array}$ & $\begin{array}{l}\text { Expected cases } \\
\text { Present }\end{array}$ & Confirmed cases & $\begin{array}{l}\text { Predictive value }{ }^{a} \text { (Based on confirmed cases } \\
\text { and number present for validation) (\%) }\end{array}$ & OR (95\% Cl) & $P$-value \\
\hline BAFUT & 304 & 86 & 30 & 34.9 & $0.24(0.12-0.56)$ & $<0.0001$ \\
\hline BAMENDA & 134 & 45 & 19 & 42.2 & $0.32(0.15-0.70)$ & 0.0034 \\
\hline BATIBO & 227 & 44 & 15 & 34.1 & $0.23(0.10-0.51)$ & 0.0002 \\
\hline BENGWI & 50 & 23 & 12 & 52.2 & $0.48(0.19-1.25)$ & 0.13 \\
\hline NDOP & 232 & 75 & 52 & 70.0 & Ref & Ref \\
\hline TUBAH & 122 & 53 & 30 & 57.0 & $0.58(0.28-1.20)$ & 0.14 \\
\hline Overall total & 1069 & 326 & 158 & 48.5 & & \\
\hline
\end{tabular}

${ }^{\mathrm{a}} \mathrm{X} 2=25.30, P=0.0001$ 
Table 4 Odd of accurately detecting podoconiosis by CHls taking stage 2 (early disease stage) as reference

\begin{tabular}{|c|c|c|c|c|}
\hline Disease stage & Correct & Incorrect & OR (95\% confidence interval) & $P$-value \\
\hline Stage 2 & 33 & 75 & Ref & Ref \\
\hline Stage 3 & 28 & 33 & $1.928[1.01-3.69]$ & 0.047 \\
\hline Stage 4 & 9 & 11 & $1.860[0.70-4.91]$ & 0.211 \\
\hline Stage 5 & 4 & 1 & $9.091[0.97-84.47]$ & 0.052 \\
\hline Advanced stages $(3,4,5)$ & 41 & 45 & $2.07[1.15-3.75]$ & 0.015 \\
\hline
\end{tabular}

in these districts. It should also be pointed out that a higher number of CHWs were employed in those Health Districts and this could equally explain the high PPVs registered. This observation implies that increasing the number of trained $\mathrm{CHW}$ would help to improve the PPV.

Evaluations of Community Health Worker performance in Kenya found that guideline complexity and inadequate supervision were major inhibitory factors [26, 27]. In addition to adequate supervision, selection and support of CHIs may also constitute a confounding factor for their performance. By definition, CHIs are individuals living in the community where they work and selected by the community to which they are answerable for their activities $[4,10]$. However, this is not always the case. Evaluation of some health intervention programmes in some low-income countries revealed that as a rule, local bureaucrats, village chiefs or other dignitaries held sway over who was selected $[26,28]$. This is a problem, as selection is often considered a form of patronage. In our study, CHIs were a subset of the Community Drug Distributors who had been working for years with the community in the framework of the mass treatment with ivermectin against onchocerciasis. It is worth mentioning that the CHI subset was selected by the health system with the help of the health committee; so some CHI worked in communities that were not their own, which might have accounted for the low performance seen in some districts.

Overall, many CHIs were happy to do the work, particularly with the training and working materials (umbrella, boots, registers and pens) given to them. However, some complained about the amount of work they were to carry out, the limited length of time that was allocated to do the work and the inadequate remuneration. From discussion with the research team, it appeared that some CHIs who attended the training did not do the work themselves but trained other persons (including their family members) in the community to work for them. The main reason was that they had had a more lucrative job somewhere else hence the need for more support to CHIs. These are some of the factors that might have led to the low predictive value obtained in some areas. In Ethiopia, CPAs are paid a monthly salary by MFTPA [29]. According to Bhattacharyya et al. [30], incentives could be both pecuniary or/and non-pecuniary depending on the setting. The effectiveness of a $\mathrm{CHI}$ comes down to his or her relationship with the community. Programmes implementers or the government must do everything they can to strengthen and support this relationship.

Another point to raise is that the approach used by CHIs to screen the community for podoconiosis was different from the one employed by the research team for validation. CHIs' screening was community-based whereas the validation was clinic-based. Provisionally identified cases were invited to the health centre for re-examination. Some real podoconiosis cases might have been missed by the researchers, those who failed to come to the health centre for comfirmation. Reluctance to attend an external venue may also arise from felt or enacted stigma. Podoconiosis is a stigmatized disease [12, 29, 31], which according to Deribe and colleagues [29] can be classified into felt and enacted. Enacted stigma includes the experience of discrimination such as abuse, loss of employment or prejudicial attitudes, while felt stigma is the perceived fear of enacted stigma. A study carried out in North West Cameroon to explore knowledge, attitudes and perceptions (KAP) relating to lymphoedema demonstrated high levels of stigma with a negative effect on free interaction and acceptance in marriage resulting in many patients staying constantly indoors [20]. A community-based validation may have led to increased $\mathrm{CHI}$ predictive value. The

Table 5 Percent agreement expressed per podoconiosis stage

\begin{tabular}{cllll}
\hline Severity of the affection & Expected cases invited (by CHIs) & Expected Cases Present & $\begin{array}{c}\text { Confirmed cases } \\
\text { Stage 2 }\end{array}$ & $\begin{array}{l}\text { Predictive value (Based on confirmed cases } \\
\text { and number present for validation) (\%) }\end{array}$ \\
\hline Stage 3 & 304 & 108 & 33 & 31 \\
Stage 4 & 207 & 61 & 28 & 46 \\
Stage 5 & 59 & 20 & 9 & 45 \\
\hline
\end{tabular}


use of treated patients by the MFTPA in Ethiopia for social work probably reduces stigma in the community while enhancing mobilization [25].

\section{Conclusion}

This study has demonstrated that CHIs given brief training identify true positive podoconiosis cases although with relatively low accuracy. Podoconiosis being a stigmatized disease, the use of CHIs (people familiar to the community) seems appropriate for the identification of cases. However, to improve the effectiveness and accuracy of $\mathrm{CHI}$ diagnosis, more training, supervision and support whether from the intervention programme implementers, the government or the community itself is very necessary. Clear indicators for assessing podoconiosis elimination and endemicity has previously been defined [32, 33].

CHIs involvement could contribute to the rapid determination of the geographical distribution of the disease which in turn would lead to successful targeting of control measures to areas of greatest need.

\section{Acknowledgments}

The authors wish to thank:

-The Ministry of Public Health, Cameroon, north-west regional delegation of health, the district medical officers and the chiefs of various health centres for their assistance and support during this field exercise.

- The community heads and community health implementers for their support and inputs.

- The populations of the Bafut, Bamenda, Batibo, Mbengwi, Ndop, Tubah health districts (North West region Cameroon) who willingly participated in this study.

- All those who helped in the execution of this study, and particularly Mr (s) J. Bonekeh, E. Dim, N. Nkemkang, S. Saidou, Enuh Blaise, Mbuh Salioh, Nchanji Gordon, Miss F. Malange, A. Chia and all the REFOTDE and Mbebah Vigilantic Farming and Development Association (MVIFAD) members.

\section{Funding}

This work was supported by the Wellcome Trust, UK [grant number 091956] to GD. The funding body had no direct role in the study design, the collection, analysis or interpretation of data, or the writing or submission of this manuscript for publication.

\section{Availability of data and materials}

Data and materials from this study can be obtained from the corresponding author on reasonable request.

\section{Authors' contributions}

Conceived and designed the study: SW, DG JAKO, PAE, MJN Conducted training of CHIs and COCs; coordinated CHIs activities in the field: JAKO, FRDP, AJN, DDSF, YFLT PAE, SW. Confirmed podoconiosis cases presumably identified by CHIs: JAKO, GD, NAA, BAF, NT PAE. Analyzed and interpreted the data: JAKO, FRDP, FTA, AJN, SW. Wrote the paper: JAKO, SW, DG. Read critically the paper and approved final version: JAKO, FRDP, AJN, DBT, DDSF, NAA, BAF, YFLT NT, FTA, PAE, MJN, GD, SW. All authors read and approved the final manuscript.

\section{Competing interests}

The authors declare that they have no competing interest.

\section{Consent for publication}

'Not Applicable'.

\section{Ethics approval and consent to participate}

The study protocol was approved by the "National Ethics Committee of Research for Human Health", Yaoundé, Cameroon. Administrative clearance was obtained from the delegation of public health of the North West region. Participation was strictly voluntary and the objectives, risks and benefits of the study were fully explained to all the participants on perceptions of consent, permission structures and approaches to the community in North West Cameroon. Each study participant gave a written consent.

\section{Author details}

${ }^{1}$ Parasites and Vector Biology research unit (PAVBRU), Department of Microbiology and Parasitology, University of Buea, Buea, Cameroon. ${ }^{2}$ Research Foundation for Tropical Diseases and the Environment (REFOTDE), Buea, Cameroon. ${ }^{3}$ Department of Biochemistry and Molecular Biology, University of Buea, Buea, Cameroon. ${ }^{4}$ Laboratory of Parasitology and Ecology, Department of Animal Biology and Physiology, University of Yaoundé I, Yaounde, Cameroon. ${ }^{5}$ Center for Research on Genomics and Global Health, National Human Genome Research Institute, National Institutes of Health, Bethesda, MD, USA. ${ }^{6}$ Wellcome Trust Centre for Global Health Research, Brighton and Sussex Medical School, Falmer Campus, Brighton BN1 9PX, UK.

Received: 5 September 2015 Accepted: 13 September 2016

Published online: 20 September 2016

\section{References}

1. Sherrill W, Crew L, Mayo RB, Mayo WF, Rogers BL, Haynes DF. Educational and health services innovation to improve care for rural Hispanic communities in the USA. Rural Remote Health. 2005;5(4):402.

2. Berman PA, Gwatkin DR, Burger SE. Community-based health workers: Head start or false start towards health for all? Soc Sci Med. 1987;25(5):443-59.

3. Lehmann U, Sanders D. Community health workers: What do we know about them? The state of the evidence on programmes, activities, costs and impact on health outcomes of using community health Workers. WHO report Evidence and Information for Policy. Geneva: Department of Human Resources for Health; 2007

4. WHO. Strengthening the performance of community health workers in primary health care. Report of a WHO Study Group. Geneva: World Health Organization; 1989. WHO Technical Report Series, No 780.

5. Love MB, Gardner K, Legion V. Community health workers: who they are and what they do. Health Educ Behav. 1997;24(4):510-22.

6. The_C. D. I._Study_Group. Community-directed interventions for priority health problems in Africa: results of a multicountry study. Bull World Health Organ. 2010;88(7):509-18.

7. Desta K, Ashine M, Davey G. Predictive value of clinical assessment of patients with podoconiosis in an endemic community setting. Trans R Soc Trop Med Hyg. 2007:101(6):621-3.

8. Yach D, Hoogendoorn L, Von Schirnding YE. Village health workers are able to teach mothers how to safely prepare sugar/salt solutions. Paediatr Perinat Epidemiol. 1987;1(2):153-61.

9. Cufino Svitone E, Garfield R, Vasconcelos Ml, Araujo Craveiro V. Primary health care lessons from the northeast of Brazil: the Agentes de Saude Program. Rev Panam Salud Publica. 2000;7(5):293-302.

10. Gaziano TA, Abrahams-Gessel S, Denman CA, Montano CM, Khanam M, Puoane T, Levitt NS. An assessment of community health workers' ability to screen for cardiovascular disease risk with a simple, non-invasive risk assessment instrument in Bangladesh, Guatemala, Mexico, and South Africa: an observational study. Lancet Glob health. 2015;3(9):e556-563.

11. Price EW. Endemic Elephantiasis: early signs and symptoms, and control. Ethiop Med J. 1983:21:243-53.

12. Davey G, Tekola F, Newport MJ. Podoconiosis: non-infectious geochemical elephantiasis. Trans R Soc Trop Med Hyg. 2007:101(12):1175-80.

13. Addiss DG. Global elimination of lymphatic filariasis: addressing the public health problem. PLoS Negl Trop Dis. 2010;4(6):e741.

14. Shawa S, Mwase E, Pedersen E, Simonsen P. Lymphatic filariasis in Luangwa District, South-East Zambia. Parasites \& Vectors. 2013;6(1):299.

15. Shenoy RK. Clinical and pathological aspects of filarial lymphedema and its management. Korean J Parasitol. 2008;46(3):119-25.

16. Price EW. Endemic Elephantiasis of the lower legs in Rwanda and Burundi. Trop Geogr Med. 1976;28:283-90.

17. Deribe K, Cano J, Newport MJ, Golding N, Pullan RL, Sime H, Gebretsadik A, Assefa A, Kebede A, Hailu A, et al. Mapping and modelling the geographical 
distribution and environmental limits of podoconiosis in Ethiopia. PLoS Negl Trop Dis. 2015;9(7):e0003946.

18. Tekola F, Ayele Z, HaileMariam D, Fuller C, Davey G. Development and testing of a de novo clinical staging system for podoconiosis (endemic non-filarial elephantiasis). Trop Med Int Health. 2008;13(10):1277-83.

19. Price, E. W. \& Henderson W. J. (1981). Endemic elephantiasis of the lower legs in the United Cameroon Republic. Tropical. Geographical Medicine 33, 23-29.

20. Wanji S, Tendongfor N, Esum M, Che JN, Mand S, Mbi CT, Enyong P, Hoerauf A. Elephantiasis of non-filarial origin (podoconiosis) in the highlands of north-western Cameroon. Ann Trop Med Parasitol. 2008;102(6):529-40.

21. Kloos H, Bedri Kello A, Addus A. Podoconiosis (endemic non-filarial elephantiasis) in two resettlement schemes in western Ethiopia. Trop Doct 1992;22(3):109-12.

22. Kengne-Ouafo JA, Nji TM, Tantoh WF, Nyoh DN, Tendongfor N, Enyong PA, Newport MJ, Davey G, Wanji S. Perceptions of consent, permission structures and approaches to the community: a rapid ethical assessment performed in North West Cameroon. BMC Public Health. 2014;14:1026.

23. Jacob KS, Senthil Kumar P, Gayathri K, Abraham S, Prince MJ. Can health workers diagnose dementia in the community? Acta Psychiatr Scand. 2007;116(2):125-8.

24. Destas, K., Ashine, M., Davey, G. (2003). Prevalence of podoconiosis (endemic non-filarial elephantiasis) in Wolaitta, Southern Ethiopia. Tropical Doctor 32, 217-220

25. Davey G, Burridge E. Community-based control of a neglected tropical disease: the mossy foot treatment and prevention association. PLoS Negl Trop Dis. 2009;3(5):e424.

26. Gilson L, Walt G, Heggenhougen K, Owuor-Omondi L, Perera M, Ross D, Salazar L. National community health worker programs: how can they be strengthened? J Public Health Policy. 1989;10(4):518-32.

27. Kelly JM, Osamba B, Garg RM, Hamel MJ, Lewis JJ, Rowe SY, Rowe AK, Deming MS. Community health worker performance in the management of multiple childhood illnesses: Siaya District, Kenya, 1997-2001. Am J Public Health. 2001;91(10):1617-24.

28. SOCHARA: An external evaluative study of the State Health Resource Centre (SHRC) and the Mitanin Programme. Final report Bangalore, Society for Community Health Awareness, Research and Action (SOCHARA) 2005, Available at: https://sochara.files.wordpress.com/2013/10/study-report-ofmitanin-prg-2005-by-shrc-chc.pdf. Accessed Aug 2015.

29. Tora A, Franklin H, Deribe K, Reda AA, Davey G. Extent of podoconiosisrelated stigma in Wolaita Zone, Southern Ethiopia: a cross-sectional study. SpringerPlus. 2014;3:647.

30. Bhattacharyya K, Winch P, LeBan K, Tien M. Community health worker incentives and disincentives: how they affect motivation, retention and sustainability. Arlington: BASICS/USAID; 2001. Report available at: www. popline.org/node/235369.

31. Tekola F, Bull S, Farsides B, Newport MJ, Adeyemo A, Rotimi CN, Davey G. Impact of social stigma on the process of obtaining informed consent for genetic research on podoconiosis: a qualitative study. BMC Med Ethics. 2009:10:13.

32. Deribe K, Wanji S, Shafi O, Muheki Tukahebwa E, Umulisa I, Davey G. Measuring elimination of podoconiosis, endemicity classifications, case definition and targets: an international Delphi exercise. Int Health. 2015;7(5):306-16.

33. Deribe K, Wanji S, Shafi O, Tukahebwa EM, Umulisa I, Molyneuxf DH, Daveya G. The feasibility of eliminating podoconiosis. Bull World Health Organ. 2015;93(10):712-8. Article ID: BLT.14.150276.

\section{Submit your next manuscript to BioMed Central and we will help you at every step:}

- We accept pre-submission inquiries

- Our selector tool helps you to find the most relevant journal

- We provide round the clock customer support

- Convenient online submission

- Thorough peer review

- Inclusion in PubMed and all major indexing services

- Maximum visibility for your research

Submit your manuscript at www.biomedcentral.com/submit
Biomed Central 